\title{
Bortezomib with Thalidomide plus Dexamethasone Compared with Thalidomide plus Doxorubicin and Dexamethasone as Induction Therapy in Previously Untreated Multiple Myeloma Patients
}

\author{
Gabriele Buda Enrico Orciuolo Giovanni Carulli Sara Galimberti Francesco Ghio \\ Giulia Cervetti Matteo Pelosini Mario Petrini
}

Department of Oncology, Transplants and Advanced Technologies, Section of Hematology, Pisa University,

Pisa, Italy

\section{Key Words}

Bone marrow transplant · Multiple myeloma - Thalidomide, bortezomib and dexamethasone $\cdot$ Thalidomide plus

doxorubicin and dexamethasone

\begin{abstract}
We conducted a retrospective study to compare thalidomide, bortezomib and dexamethasone (VTD) with thalidomide plus doxorubicin and dexamethasone (TAD). Until now, first-line treatment with these combinations has not been reported in any comparative study. The principal objective of this study was to determine whether VTD would improve the complete response (CR) and CR plus very good partial response rates compared with TAD. Second, using additional methods, such as flow cytometric assays and polymerase chain reaction technology, we evaluated the molecular residual disease in the subgroup of patients that obtained CR. Our study shows that VTD is a superior induction regimen compared with TAD, with a higher response rate after induction, translating into greater CR plus very good partial response.

Copyright $\odot 2012$ S. Karger AG, Basel
\end{abstract}

\section{KARGER}

Fax +4161306 1234

E-Mail karger@karger.ch

www.karger.com
(C) 2012 S. Karger AG, Basel

0001-5792/13/1291-0035\$38.00/0

Accessible online at:

www.karger.com/aha

\section{Introduction}

High-dose therapy plus autologous stem cell transplantation (HDT/ASCT) is commonly considered the standard of care for frontline treatment in younger patients with multiple myeloma (MM) [1]. In the context of HDT/ASCT, achievement of complete response (CR) or at least very good partial response (VGPR) is associated with an improved outcome [2-5]. One strategy to increase the CR plus VGPR rate in the HDT/ASCT paradigm is to improve induction treatment. Before the era of novel therapies, induction treatment typically consisted of high-dose dexamethasone alone or combined with vincristine and adriamycin (VAD). Compared with dexamethasone or VAD, the combination of thalidomide and dexamethasone as induction treatment increased the overall response rate but failed to increase the $\mathrm{CR}$ rate before HDT/ASCT or the CR plus VGPR rate after ASCT $[6,7]$. A randomized trial showed that compared with

\section{G.B. and E.O. contributed equally to this work.}

Dr. Gabriele Buda

Section of Hematology, Pisa University

via Roma 67

IT-56100 Pisa (Italy)

Tel. +39050992 755, E-Mail ga.buda@libero.it 
VAD, bortezomib plus dexamethasone (VD) significantly improved CR plus VGPR before HDT/ASCT [8]. A three-drug combination including one novel agent, such as thalidomide plus doxorubicin and dexamethasone (TAD), has also been found to be superior to VAD or VAD-like regimens. Recently, the most promising results have been obtained with a three-drug regimen consisting of thalidomide, bortezomib and dexamethasone (VTD) [9-11]. The objective of any new induction regimen should be to provide best efficacy while limiting toxicity. The high rate of CR effected by novel agents as induction therapy has also renewed interest in the evaluation of minimal residual disease (MRD) after these combined treatment strategies [12]. In our hospital, we conducted a retrospective study to compare VTD with TAD. Until now, first-line treatment with these combinations has not been reported in any comparative study. The principal objective of this study was to determine whether the combination of VTD would improve the CR and CR plus VGPR rates compared with TAD. Secondary, using additional methods, such as flow cytometric (FC) assays and polymerase chain reaction (PCR) technology, we evaluated the MRD in the subgroup of patients that obtained CR.

\section{Patients and Methods}

We retrospectively evaluated $87 \mathrm{MM}$ patients treated in our department between February 2007 and September 2011 eligible for autologous transplant. Patients were 29-73 years of age (median 61) and had untreated, newly diagnosed and symptomatic MM. Evaluation of disease was based on a variety of laboratory techniques, including bone marrow biopsy, morphology, immunophenotyping, molecular IgH rearrangements, analysis of serum or urine $\mathrm{M}$-component and free light chains (paraprotein in serum $>1 \mathrm{~g} / \mathrm{dl}$ or urine $>0.2 \mathrm{~g} / 24 \mathrm{~h}$ ), hematological and biochemical parameters and cytogenetics. All patients provided written informed consent in accordance with the International Conference on Harmonization of Good Clinical Practice Guidelines and the principles of the Declaration of Helsinki. Patients were treated with 4 cycles of TAD or VTD (TAD if patients were treated between February 2007 and August 2009, and VTD if treated between September 2009 and 2011). TAD consisted of 4 cycles of intravenous doxorubicin on day 1 every 28 days in day hospital, dexamethasone $40 \mathrm{mg}$ orally on days 1-4 and 9-12, and thalidomide $100 \mathrm{mg} /$ day continuously and orally administered. VTD consisted of four 3-week cycles of bortezomib $1.3 \mathrm{mg} / \mathrm{m}^{2} \mathrm{admin}$ istered intravenously on days 1, 4, 8 and 11 plus dexamethasone $40 \mathrm{mg}$ on days 1 and 2 as well as on days 3 and 4,8 and 9, and 11 and 12 (all cycles), and thalidomide $100 \mathrm{mg}$ /day continuously and orally administered. Recommended concomitant medications included bisphosphonates, antibiotics, erythroid or granulocytic growth factor and antiviral prophylaxis in accordance with stan- dard practice. After induction, in respondent patients, stem cells were mobilized with cyclophosphamide $3 \mathrm{~g} / \mathrm{m}^{2}$ plus granulocyte colony-stimulating factor $10 \mu \mathrm{g} / \mathrm{kg}$. The target yield was $3.5 \times$ $10^{6} \mathrm{CD} 34+$ cells $/ \mathrm{kg}$. The primary endpoint was postinduction CR plus VGPR rates. The secondary endpoint was evaluation of MRD in patients that obtained CR. Response was evaluated according to the International Myeloma Working Group uniform criteria [13]. Adverse events were graded by the National Cancer Institute Common Toxicity Criteria, version 3.0. Blood and 24-hour urine samples were taken at baseline, before each induction cycle and 1 month after cycle 4. FC assays and PCR, on bone marrow samples, were performed at diagnosis and 1 month after cycle 4 . The endpoint targets (postinduction CR and VGPR rates) were performed using a $\chi^{2}$ test. For the postinduction CR and CR plus VGPR rates, prognostic factors for response were investigated using logistic regression analysis, adjusted for treatment to check whether the absence or the presence of a difference between the response rates for VTD and TAD was confirmed when taking into account factors significantly related to response. Specifically, the following factors were tested: $\beta_{2}$-microglobulin level and cytogenetics.

\section{Flow Cytometry Assay and PCR Technology}

Immunophenotyping was carried out by a FacsCanto II cytometer equipped with 3 lasers (405, 488 and $633 \mathrm{~nm})$. A sevencolor method was used, with monoclonal antibodies conjugated with the following fluorochromes: FITC, PE, PercCP-Cy5.5, PeCy.7, APC, APC-Cy.7 and AmCyan.

Bone marrow samples were stained with $1 \mu \mathrm{g}$ of each monoclonal antibody and a lyse/no-wash method was carried out after incubation. A total of 500,000 events/tube were acquired and plasma cells were identified by means of a CD138 versus CD38 analysis, which provided the best separation of plasma cells from other leukocytes. A second gate included events with homogeneous forward scatter and side scatter properties, and a third gate included CD38+ events after analysis of a CD38/CD45 dot plot. The three gates were intersected to obtain a well-defined plasma cell population $[14,15]$. Abnormal plasma cells were defined as CD19- and clonality assessment by cytoplasmic immunoglobulin $\kappa$ or $\lambda$ light chains. Negativity for CD27 and CD81 and/or positivity for CD20, CD10, CD117 and CD56 were useful additional markers of abnormality [16]. A cluster of at least 50 events was considered significant, and MRD was set at $0.01 \%$ abnormal plasma cells [17]. Data were analyzed by the FacsDiva software.

PCR analyses were performed on mononuclear cells separated by Ficoll/Hypaque gradient. High-molecular-weight DNA was extracted, and suitable aliquots were utilized for PCR assays to identify bone marrow infiltration represented by clonal IgH rearrangement. Every PCR procedure included both negative (distilled water) and positive control (DNA carrying monoclonal IgH rearrangement). To reduce false-negative results, six independent IgH PCRs were performed using $\mathrm{V}_{\mathrm{H}}$ family-specific sense primers and a JH consensus primer, as previously described by Willems et al. [18]. Samples were prepared for analysis by mixing $1 \mu$ l of PCR products with $15 \mu \mathrm{l}$ of deionized formamide (Amresco) and 0.5 $\mu l$ Gene Scan ${ }^{\mathrm{TM}} 500$ Tamra-labeled internal standard (Applera). The mixture was denatured at $95^{\circ} \mathrm{C}$ for $2 \mathrm{~min}$ and then quickly cooled on ice. Capillary electrophoresis and fluorescence detection with a virtual filter $C$ was performed using an ABI Prism 310 Genetic Analyzer (Applied Biosystems). Runs were executed with the module GS STR POP $4(1 \mathrm{ml}) \mathrm{C}$, with 10 -second and $15-\mathrm{kV}$ 
injection and run voltage, $60^{\circ} \mathrm{C}$ constant temperature, 24 -min run time, using polymer POP 4 and the running buffer Genetic Analyzer 1X (Applied Biosystems). Genescan 2.1 software was then used to analyze the PCR products, with accurate sizing and quantification of the peak areas, according to our previously published method [19].

\section{Results}

A total of 87 patients were treated and received TAD (44 patients) or VTD (43 patients). Baseline characteristics are summarized in table 1 . No significant difference was observed between the two groups. Data on cytogenetic abnormalities, including $\operatorname{del}(13 \mathrm{q}), \mathrm{t}(4 ; 14)$ and del(17p), detected by fluorescence in situ hybridization, were available in $>90 \%$ of patients. Both VTD and TAD regimens were well tolerated. Rates of CR and VGPR or better were significantly higher after induction therapy with VTD than with TAD (table 2). Only 1 patient treated with VTD had disease progression during induction therapy. After $4 \mathrm{cy}-$ cles, the overall response rate was $91 \%$ in the VTD group versus $84 \%$ in the TAD group (table 2 ). The difference in the overall response rate between the VTD and TAD arms was 7\%. However, the CR plus VGPR rate was significantly higher in the VTD arm (51 vs. $18 \%$; $=0.001$ ). The difference in the CR plus VGPR rates between the VTD and TAD arms was 33\%. The difference in the CR rate was $28 \%$ (30\% in the VTD group vs. $2 \%$ in the TAD group). In the only patient that obtained CR in the TAD group, FC and PCR were able to still detect MRD, but in 10 of 13 (77\%) patients that achieved CR in the VTD group, both additional assays confirmed the absence of MRD. The use of cyclophosphamide to mobilize stem cells did not upgrade the response to induction therapy in either arm of the study. None of the analyzed factors mentioned above was predictive for CR plus VGPR.

\section{Discussion}

In MM, the goal of induction treatment before HDT/ ASCT is to achieve the highest possible response rate while avoiding impairment of stem cell collection and significant toxicity that could preclude intensive therapy [20]. A small fraction of patients unexpectedly lose their CR status during the first year after HDT/ASCT and experience a dismal survival rate. VD is frequently considered the cornerstone of induction, and several triplet combinations have been developed based on this backbone, such as VD plus doxorubicin, VD plus cyclophosphamide,
Table 1. Patient characteristics

\begin{tabular}{lllll}
\hline & & TAD & VTD & Total \\
\hline Patients & & 44 & 43 & 87 \\
\hline Sex & Male & $18(41)$ & $24(56)$ & 42 \\
& Female & $26(59)$ & $19(44)$ & 45 \\
\hline Age at diagnosis, & Median age & 61 & 60 & 61 \\
years & Range & $35-73$ & $29-72$ & $29-73$ \\
\hline MM subtype & IgA & 8 & 11 & 19 \\
& IgG & 32 & 28 & 60 \\
& LCD & 4 & 3 & 7 \\
\hline ISS & NS & 0 & 1 & 1 \\
\hline Stage (Durie and & I & 27 & 25 & 52 \\
Salmon) & II & 7 & 8 & 15 \\
& II & 8 & 10 & 20 \\
\hline Karyotype & III & 30 & 35 & 65 \\
& Normal & 35 & 36 & 71 \\
& Abnormal & 9 & 7 & 16 \\
\hline
\end{tabular}

Figures in parentheses are percentages. $\mathrm{LCD}=$ Light chain disease; NS = non-secretory; ISS = International Staging System.

Table 2. Response rates

\begin{tabular}{lcc}
\hline & TAD & VTD \\
\hline CR & $1(2)$ & $13(30)$ \\
VGPR & $7(16)$ & $9(21)$ \\
PR & $29(66)$ & $17(40)$ \\
SD & $5(11)$ & $3(7)$ \\
PD & $2(5)$ & $1(2)$ \\
\hline
\end{tabular}

Figures in parentheses are percentages. $\mathrm{PR}=$ Partial response; $\mathrm{SD}=$ stable disease; $\mathrm{PD}=$ progressive disease.

VD plus thalidomide (VTD), or VD plus lenalidomide [21]. Recently, VTD has been prospectively compared with TD [12] and with VBMCP/VBAP/bortezomib [13], and the efficacy results of these 2 studies are in favor of VTD. Until recently, no direct comparison of TAD versus VTD was available. In our study, patients with previously untreated myeloma who were eligible for transplant, induction therapy with VTD significantly improved clinical outcomes compared with TAD therapy in patients eligible for autologous stem cell transplantation. 
The CR plus VGPR rate after 4 cycles was significantly increased in the VTD arm compared with the TAD arm. Several studies have already demonstrated that achievement of VGPR before ASCT is an important prognostic factor and is therefore a key objective, and that the choice of best induction therapy is of great importance $[2,3,5,22]$. Our VTD efficacy results are in line with those achieved in prospective studies conducted by Italian and Spanish groups. In the Italian prospective study, the VTD regimen was compared to TD. After induction therapy, CR or near CR was achieved in 73 patients $(31 \%)$ receiving VTD, and in $27(11 \%)$ of the TD group ( $\mathrm{p}<0.0001)$ [23]. In the 3 -arm randomized Spanish study (PETHEMA GEM05MENOS65), 6 cycles of VTD as induction were compared with 6 cycles of TD, and with 4 cycles of VBMCP/VBAP followed by 2 cycles of bortezomib. VTD yielded a $60 \%$ VGPR rate versus $29 \%$ in the TD arm and $36 \%$ in the third arm of the trial [12]. In our study, both VTD and TAD regimens were well tolerated, with doses during induction and consolidation therapy very close to the planned doses. Side ef- fects, including peripheral neuropathy were manageable during induction therapy. These data also suggest that the combination of bortezomib with thalidomide does not result in additive neurological toxic effects. The high rate of CR effected by novel agents as induction therapy in $\mathrm{MM}$ has renewed interest in the evaluation of MRD after these combined treatment strategies, and the VTD regimen seems to be able to induce a very high rate of CR including undetected MRD evaluated with two different analyses. Incorporation of novel agents in induction therapy of patients with myeloma has improved the CR and VGPR rates. In conclusion, our study shows that VTD is a superior induction regimen compared with TAD, with a higher response rate after induction, translating into a greater CR plus VGPR. Additionally, we have shown that when highly sensitive techniques are used, MRD is undetectable in an important fraction of patients in CR after VTD. Therefore, VTD represents a new standard of care to maximize the degree and speed of tumor reduction in patients with myeloma who are eligible for transplant.

\section{References}

1 Attal M, Harousseau JL, Stoppa AM, Sotto JJ, Fuzibet JG, Rossi JF, Casassus P, Maisonneuve $\mathrm{H}$, Facon T, Ifrah N, Payen C, Bataille $\mathrm{R}$ : A prospective, randomized trial of autologous bone marrow transplantation and chemotherapy in multiple myeloma: Intergroupe Francais du Myelome. N Engl J Med 1996;335:91-97.

-2 Van de Velde HJ, Liu X, Chen G, Cakana A, Deraedt W, Bayssas M: Complete response correlates with long-term survival and progression-free survival in high-dose therapy in multiple myeloma. Haematologica 2007; 92:1399-1406.

-3 Lahuerta JJ, Mateos MV, Martínez-López J, Rosiñol L, Sureda A, de la Rubia J, GarcíaLaraña J, Martínez-Martínez R, HernándezGarcía MT, Carrera D, Besalduch J, de Arriba F, Ribera JM, Escoda L, Hernández-Ruiz B, García-Frade J, Rivas-González C, Alegre A, Bladé J, San Miguel JF: Influence of preand post-transplantation responses on outcome of patients with multiple myeloma: sequential improvement of response and achievement of complete response are associated with longer survival. J Clin Oncol 2008;26:5775-5782.

$\checkmark 4$ Harousseau JL, Attal M, Avet-Loiseau H: The role of complete response in multiple myeloma. Blood 2009;114:3139-3146.
5 Chanan-Kahn A, Giralt S: Importance of achieving a complete response in multiple myeloma, and the impact of novel agents. J Clin Oncol 2010;28:2612-2624.

$\checkmark 6$ Cavo M, Zamagni E, Tosi P, Tacchetti P, Cellini C, Cangini D, de Vivo A, Testoni N, Nicci C, Terragna C, Grafone T, Perrone G, Ceccolini M, Tura S, Baccarani M, Bologna 2002 study: Superiority of thalidomide and dexamethasone over vincristine-doxorubicinedexamethasone (VAD) as primary therapy in preparation for autologous transplantation for multiple myeloma. Blood 2005;106: 35-39.

7 Macro M, Divine M, Uzunban Y: Dexamethasone + thalidomide compared to VAD as pre-transplant treatment in newly diagnosed multiple myeloma: a randomized trial (abstract 57). Blood 2006;108:22a.

8 Harousseau JL, Attal M, Avet-Loiseau H, Marit G, Caillot D, Mohty M, Lenain P, Hulin C, Facon T, Casassus P, Michallet M, Maisonneuve $\mathrm{H}$, Benboubker L, Maloisel F, Petillon MO, Webb I, Mathiot C, Moreau P: Bortezomib-dexamethasone is superior to vincristine-doxorubicin-dexamethasone as induction treatment prior to autologous stem cell transplantation in newly diagnosed multiple myeloma: results of the IFM 2005-01 phase 3 trial. J Clin Oncol 2010;28:4621-4629.
9 Lokhorst HM, Schmidt-Wolf I, Sonneveld P, van der Holt B, Martin H, Barge R, Bertsch U, Schlenzka J, Bos GM, Croockewit S, Zweegman S, Breitkreutz I, Joosten P, Scheid C, van Marwijk-Kooy M, Salwender HJ, van Oers MH, Schaafsma R, Naumann R, Sinnige $\mathrm{H}$, Blau I, Delforge $\mathrm{M}$, de Weerdt $\mathrm{O}$, Wijermans P, Wittebol S, Duersen U, Vellenga E, Goldschmidt H, Dutch-Belgian HOVON, German GMMG: Thalidomide in induction treatment increases the very good partial remission rate before and after high-dose therapy in previously untreated multiple myeloma. Haematologica 2008;93:124-127.

10 Lokhorst HM, van der Holt B, Zweegman S, Vellenga E, Croockewit S, van Oers MH, von dem Borne P, Wijermans P, Schaafsma R, de Weerdt O, Wittebol S, Delforge M, Berenschot H, Bos GM, Jie KS, Sinnige H, van Marwijk-Kooy M, Joosten P, Minnema MC, van Ammerlaan R, Sonneveld P, Dutch-Belgian Hemato-Oncology Group (HOVON): A randomized phase 3 study on the effect of thalidomide combined with adriamycin, dexamethasone, and high-dose melphalan, followed by thalidomide maintenance in patients with multiple myeloma. Blood 2010; 115:1113-1120.

11 Morgan GJ, Davies FE, Owen RG: Thalidomide combinations improve response rates: results from the MRC IX study (abstract 3593). Blood 2007;110:1051a. 
12 Paiva B, Gutiérrez NC, Rosiñol L, Vídriales MB, Montalbán MÁ, Martínez-López J, Mateos MV, Cibeira MT, Cordón L, Oriol A, Terol MJ, Echeveste MA, de Paz R, de Arriba F, Palomera L, de la Rubia J, Díaz-Mediavilla J, Sureda A, Gorosquieta A, Alegre A, Martin A, Hernández MT, Lahuerta JJ, Bladé J, San Miguel JF, PETHEMA/GEM (Programa para el Estudio de la Terapéutica en Hemopatías Malignas/Grupo Español de Mieloma) Cooperative Study Groups: Highrisk cytogenetics and persistent minimal residual disease by multiparameter flow cytometry predict unsustained complete response after autologous stem cell transplantation in multiple myeloma. Blood 2012; 119:687-691.

-13 Durie BG, Harousseau JL, Miguel JS, Bladé J, Barlogie B, Anderson K, Gertz M, Dimopoulos M, Westin J, Sonneveld P, Ludwig H, Gahrton G, Beksac M, Crowley J, Belch A, Boccadaro M, Cavo M, Turesson I, Joshua D, Vesole D, Kyle R, Alexanian R, Tricot G, Attal M, Merlini G, Powles R, Richardson P, Shimizu K, Tosi P, Morgan G, Rajkumar SV, International Myeloma Working Group: International uniform response criteria for multiple myeloma. Leukemia 2006;20:14671473.

14 Rawstron AC, Davies FR, Dasgupta R, Ashcroft J, Patmore R, Drayson MT, Owen RG, Jack AS, Child JA, Morgan GJ: Flow cytometric disease monitoring in multiple myeloma: the relationship between normal and neoplastic plasma cells predicts outcome after transplantation. Blood 2002;100:30953100 .
15 Cannizzo E, Carulli G, Del Vecchio L, Ottaviano V, Bellio E, Zenari E, Azzarà A, Petrini M, Preffer F: The role of CD19 and CD27 in the diagnosis of multiple myeloma by flow cytometry. A new statistical model. Am J Clin Pathol 2012;137:377-386.

16 Rawstron AC, Orfao A, Beksac M, Bezdickova L, Brooimans RA, Bumbea H, Dalva K, Fuhler G, Gratama J, Hose D, Kovarova L, Lioznov M, Mateo G, Morilla R, Mylin AK, Omedé P, Pellat-Deceunynck C, Perez Andres M, Petrucci M, Ruggeri M, Rymkiewicz G, Schmitz A, Schreder M, Seynaeve C, Spacek M, de Tute RM, Van Valckenborgh E, Weston-Bell N, Owen RG, San Miguel JF, Sonneveld P, Johnsen HE, European Myeloma Network: Report of the European Myeloma Network on multiparametric flow cytometry in multiple myeloma and related disorders. Haematologica 2008;93:431-438.

17 Paiva B, Vidriales MB, Cerveró J, Mateo G, Pérez JJ, Montalbán MA, Sureda A, Montejano L, Gutiérrez NC, García de Coca A, de Las Heras N, Mateos MV, López-Berges MC, García-Boyero R, Galende J, Hernández J, Palomera L, Carrera D, Martínez R, de la Rubia J, Martín A, Bladé J, Lahuerta JJ, Orfao A, San Miguel JF, GEM (Grupo Español de MM)/PETHEMA (Programa para el Estudio de la Terapéutica en Hemopatías Malignas) Cooperative Study Groups: Multiparameter flow cytometric remission is the most relevant prognostic factor for multiple myeloma patients who undergo autologous stem cell transplantation. Blood 2008;112:4017-4023.

18 Willems P, Verhagen O, Segeren C, Veenhuizen P, Guikema J, Wiemer E, Groothuis L, Jong TB, Kok H, Bloem A, Bos N, Vellenga E, Mensink E, Sonneveld P, Lokhorst H, van Der Schoot E, Raymakers R: Consensus strategy to quantitate malignant cells in myeloma patients is validated in a multicenter study. Belgium-Dutch Hematology-Oncology Group. Blood 2000;96:63-70.
9 Galimberti S, Brizzi F, Mameli M, Petrini M: An advantageous method to evaluate IgH rearrangement and its role in minimal residual disease detection. Leuk Res 1999;23:921929.

20 Wang M, Giralt S, Delasalle K, Handy B, Alexanian R: Bortezomib in combination with thalidomide-dexamethasone for previously untreated multiple myeloma. Hematology 2007;12:235-239.

21 Moreau P, Avet-Loiseau H, Harousseau JL, Attal M: Current trends in autologous stem cell transplantation for myeloma in the era of novel therapies. J Clin Oncol 2011;29:18981906.

22 Moreau P, Attal M, Pégourié B, Planche L, Hulin C, Facon T, Stoppa AM, Fuzibet JG, Grosbois B, Doyen C, Ketterer N, Sebban C, Kolb B, Chaleteix C, Dib M, Voillat L, Fontan J, Garderet L, Jaubert J, Mathiot C, Esseltine $\mathrm{D}$, Avet-Loiseau $\mathrm{H}$, Harousseau JL, IFM 2005-01 study investigators: Achievement of VGPR to induction therapy is an important prognostic factor for longer PFS in the IFM2005-01 trial. Blood 2011;117:30413044.

23 Cavo M, Tacchetti P, Patriarca F, Petrucci MT, Pantani L, Galli M, Di Raimondo F, Crippa C, Zamagni E, Palumbo A, Offidani M, Corradini P, Narni F, Spadano A, Pescosta N, Deliliers GL, Ledda A, Cellini C, Caravita T, Tosi P, Baccarani M, GIMEMA Italian Myeloma Network: Bortezomib with thalidomide plus dexamethasone compared with thalidomide plus dexamethasone as induction therapy before, and consolidation therapy after, double autologous stem-cell transplantation in newly diagnosed multiple myeloma: a randomised phase 3 study. Lancet 2010;376:2075-2085. 